\title{
Anesthetic Management of a Patient with Acute Head Injury for Orthopaedic Procedure
}

\author{
Sangam Yadav ${ }^{1}$ Ashish Bindra ${ }^{2}$ Kali C. Das² \\ ${ }^{1}$ Department of Anesthesiology, Critical Care and Pain Medicine, \\ All India Institute of Medical Sciences, New Delhi, India \\ ${ }^{2}$ Neuroanesthesiology and Critical Care, All India Institute of \\ Medical Sciences, New Delhi, India
}

J Neuroanaesthesiol Crit Care 2021;8:152-153.

Although it is common to have a patient with head injury and coexistent limb fracture, anesthetic management of patients with a recent head injury for other surgeries generates discussion. There are no clear-cut guidelines for absolute dos and don'ts; the anesthetic plan is often individualized and depends on the dealing anesthesiologist and the patient condition. We describe anesthetic management of a 21-year-old man, weighing $65 \mathrm{~kg}$, who presented with a history of road traffic accident 12 hours ago. Patient's vitals were stable, Glasgow coma score was 15/15. However, there was a history of loss of consciousness and two episodes of vomiting. Noncontrast computed tomography (NCCT) head revealed right occipital bone fracture with a small extradural hematoma (EDH) ( - Fig. 1). Other injuries included compound fracture of both distal bones of the left leg, fracture of the sixth rib, and posterior degloving wound of the left leg. Conservative management was planned for the head injury and the patient was put on phenytoin prophylaxis. The limb injury required externalfixator application and wound debridement for which he was brought to the operation room (OR).

On examination, the patient was conscious, alert, and without neurological deficit. The baseline heart rate and blood pressure were $96 / \mathrm{min}$ and $110 / 60 \mathrm{~mm} \mathrm{Hg}$, respectively. His hematological and biochemical investigations were unremarkable. In view of the emergent nature of the surgery, risk of neurological deterioration was explained to the patient and intensive care unit (ICU) bed was kept as backup. In the OR, standard monitors were attached. We took advantage of the neurological status of the patient and planned for conscious sedation with peripheral nerve block, which is otherwise not commonly applicable in patients with neurotrauma. The procedure was explained to the patient. The patient was placed in left lateral decubitus and under all aseptic precautions using USG guidance poplitealsciatic nerve block was given with $12 \mathrm{~mL}$ of $0.5 \%$ bupivacaine, $11 \mathrm{~mL}$ of $2 \%$ lignocaine with adrenaline, and $8 \mathrm{mg}$

Published online June 1, 2020
DOI https://doi.org/ $10.1055 / \mathrm{s}-0040-1710703$ ISSN 2348-0548.

\begin{abstract}
Address for correspondence Ashish Bindra, MD, DM, Department of Neuroanaesthesia and Critical Care, Jai Prakash Narayan Apex Trauma Centre, All India Institute of Medical Sciences (A.I.I.M.S), New Delhi 110029, India (e-mail: dr_ashi2208@yahoo.com).
\end{abstract}

dexamethasone, which was followed by saphenous nerve block, given at tibial tuberosity on medial end of tibial shaft, with 4 $\mathrm{mL}$ of lignocaine with adrenaline, $4 \mathrm{~mL} 0.5 \%$ bupivacaine, and $4 \mathrm{mg}$ dexamethasone. The limb was adequately anesthetized and surgery went on for 195 minutes in supine position. Dexmedetomidine $0.5 \mu \mathrm{g} / \mathrm{kg}$ was given as a bolus followed by $0.5 \mu \mathrm{g} / \mathrm{kg} / \mathrm{h}$ infusion for conscious sedation. Patient was carefully watched for GCS, pupil reaction, and lateralizing signs. Since the patient had full GCS score, intracranial pressure monitoring was not done. No additional neuromonitoring was done for this case. Total blood loss was $100 \mathrm{~mL}$ and a volume of 2000 $\mathrm{mL}$ of balanced salt solution was infused. The patient remained neurologically (GCS and pupil) and hemodynamically stable intraoperatively and remained so in the postoperative period.

Not all cases of acute EDH require immediate surgical intervention. It is important to preserve cerebral homeostasis and prevent secondary insult due to coexisting injuries, intraoperative hemodynamic changes due to surgery, and anesthetic drugs especially in cases presenting without neurological deficits. Brain Trauma Foundation guidelines recommend prevention of secondary brain injury by maintenance of cerebral perfusion, preventing increase in ICP and seizures prophylaxis. Intracranial pressure monitoring is recommended in a limited set of patients. ${ }^{1}$ Most common neuromonitoring described is serial GCS, examination of pupil, and intracranial pressure whenever possible. There were no clear indications of ICP monitoring in this case. Our anesthetic plan targeted at minimal interference with systemic and neurological status of the patient. Other concerns in a polytrauma patient include addressing other associated injuries. Long bone fractures and posterior degloving injury as in our case can cause large blood loss, resulting in hypotension. Similarly, rib fractures are often associated with underlying lung contusion and cause pain and respiratory compromise.

Neuraxial block in a head injury can reduce cerebrospinal pressure and can cause intracranial hematoma expansion. 


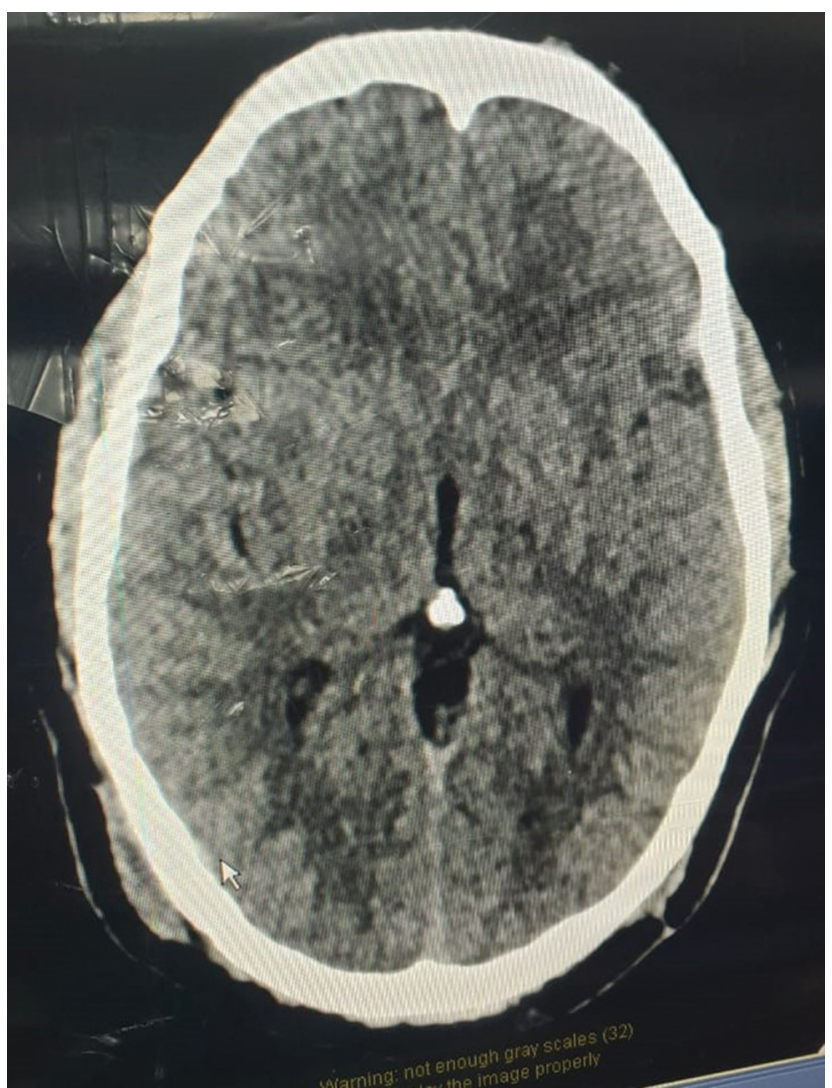

Fig. 1 Computed tomography scan of the patient, showing right occipital bone fracture with a small extradural hematoma (EDH).

General anesthesia, besides interfering with neurological examination, can result in intubation response, intraoperative hypotension/hypertension, hypoxia, and hypo/hypercarbia, which can be deleterious for intracranial and cerebral perfusion pressure. Conscious sedation with peripheral nerve block is optimal in cooperative patients. As the patient was fully conscious and cooperative, we planned for ultrasound-guided peripheral nerve block and dexmedetomidine sedation. Such a technique has several advantages like abolition of surgical stress, minimal interference with hemodynamics, and awake patient, allowing for neurological examination. Dexmedetomidine causes minimal interference with cerebral oxygenation in patients with TBI. ${ }^{2}$ Ultrasound has revolutionized peripheral nerve blocks which can be given with more certainty and effectivity while avoiding neural trauma and high drug dosage. ${ }^{3}$

Our case described feasibility of surgery under peripheral nerve blocks with conscious sedation in patients with recent head injury. Peripheral nerve block with dexmedetomidine infusion provided excellent operating conditions and ensured good systemic and cerebral hemodynamics, and conscious sedation allowed simultaneous neurological monitoring.

\section{Funding}

None.

\section{Conflict of Interest}

None declared.

\section{References}

1 Carney N, Totten AM, O'Reilly C, et al. Guidelines for the management of severe traumatic brain injury. 4 th ed. Neurosurgery 2017;80(1):6-15

2 Wang X, Ji J, Fen L, Wang A. Effects of dexmedetomidine on cerebral blood flow in critically ill patients with or without traumatic brain injury: a prospective controlled trial. Brain Inj 2013;27(13-14):1617-1622

3 Koscielniak-Nielsen ZJ. Ultrasound-guided peripheral nerve blocks: what are the benefits? Acta Anaesthesiol Scand 2008;52(6):727-737

\title{
A Diagnostic Dilemma in Combined Central Diabetes Insipidus and Cerebral Salt Wasting Syndrome
}

\author{
Jayanth Seshan ${ }^{1}$ Hirok Roy ${ }^{1}$ Charu Mahajan ${ }^{1} \quad$ Indu Kapoor ${ }^{1}$ Hemanshu Prabhakar ${ }^{1}$
}

\author{
${ }^{1}$ Department of Neuroanaesthesiology and Critical Care, All India \\ Institute of Medical Sciences, New Delhi, India
}

J Neuroanaesthesiol Crit Care 2021;8:153-154.
Address for correspondence Charu Mahajan, MD, DM, Department of Neuroanaesthesiology and Critical Care, Neurosciences Centre, All India Institute of Medical Sciences, New Delhi 110029, India (e-mail: charushrikul@gmail.com).
(C) 2020. Indian Society of Neuroanaesthesiology and Critical Care. This is an open access article published by Thieme under the terms of the Creative Commons Attribution-NonDerivative-NonCommercial-License, permitting copying and reproduction so long as the original work is given appropriate credit. Contents may not be used for commercial purposes, or adapted, remixed, transformed or built upon. (https://creativecommons.org/licenses/by-nc-nd/4.0/).

Thieme Medical and Scientific Publishers Pvt. Ltd. A-12, 2nd Floor, Sector 2, Noida-201301 UP, India 